\title{
RSK4 knockdown promotes proliferation, migration and metastasis of human breast adenocarcinoma cells
}

\author{
JIA ZHU* , QIU-YUN LI ${ }^{*}$, JIAN-LUN LIU, WEI WEI, HUA-WEI YANG and WEI TANG \\ Department of Breast Surgery, The Affiliated Tumor Hospital of \\ Guangxi Medical University, Nanning, Guangxi 530021, P.R. China
}

Received June 24, 2015; Accepted August 3, 2015

DOI: $10.3892 /$ or.2015.4291

\begin{abstract}
RSK4 has been shown to inhibit the growth of certain cancer cells. The aim of this study was to construct a lentiviral vector of RSK4-shRNA (Lenti-RSK4-shRNA) to specifically block the expression of RSK4 in the human breast adenocarcinoma cell line MCF-7, and investigate the effect of the RSK4 gene on cell proliferation and invasion in vitro and in vivo. Lenti-RSK4-shRNA was stably transfected into MCF-7 cells. RSK4 mRNA and protein expression were measured by fluorescence quantitative RT-PCR and western blot analysis. Cell proliferation was evaluated by MTT assays and flow cytometric analysis. Invasion was evaluated by Transwell assays and xenograft nude mouse models. The expression of RSK4 mRNA, Ki-67 mRNA, cyclin D1 mRNA, CXCR4 mRNA and E-cadherin mRNA of tumor xenografts were detected by fluorescence quantitative RT-PCR. Significant decreases in RSK4 mRNA and protein expression was detected in MCF-7 cells carrying lentiviral RSK4-shRNA vector. The cell proliferation was significantly promoted in the RSK4-shRNA group as compared to that in the negative and blank control group. In addition, the number of cells in the $S$ phase in the RSK4-shRNA group was significantly greater than the blank and negative control groups $(\mathrm{P}<0.05)$. Furthermore, the number of invading cells was increased in the RSK4-shRNA $(\mathrm{P}<0.05)$. In vivo, we also found that the knockdown of RSK4 promoted tumorigenicity and migration in the xenograft nude mouse model. In addition, we showed that the RSK4 mRNA and E-cadherin mRNA expression were significantly lower in the RSK4-shRNA group compared to that in negative and blank control group (both $\mathrm{P}<0.05$ ), while the Ki-67 mRNA, cyclin D1 mRNA and CXCR4 mRNA were higher in the shRNA group compared to that in negative and blank control group (both $\mathrm{P}<0.05)$. In conclusion, downregulation of RSK4 expression is indicated to be associated with tumor cell proliferation and
\end{abstract}

Correspondence to: Professor Jian-Lun Liu, Department of Breast Surgery, The Affiliated Tumor Hospital of Guangxi Medical University, Nanning, Guangxi 530021, P.R. China

E-mail: jianlunliu@hotmail.com

${ }^{*}$ Contributed equally

Key words: RSK4, breast adenocarcinoma, lentivirus, shRNA invasion, and silencing of the RSK4 may be involved in the development and progression of breast cancer through the changes of Ki-67, cyclin D1, CXCR4 and E-cadherin, and suggesting that RSK4 may act as a potential cancer suppressor gene and therapeutic target for the treatment of breast cancer.

\section{Introduction}

Breast cancer is one of the most common cancers and the leading cause of cancer death in females, accounting for $23 \%$ of the total cancer cases and $14 \%$ of the cancer deaths, and the incidence is still increasing (1). The major dilemma is that many women suffering from breast cancer end up with metastatic breast cancer (MBC) and recurrence, even though they all received surgery, adjuvant chemotherapy or/and radiotherapy (2). At present, with better understanding of breast cancer progression with molecular markers such as Her-2, VEGF and EGFR, the treatment of breast cancer has entered a new era of molecular targeted therapy, from which more and more patients could benefit (3). Due to heterogeneity of breast tumor, the current treatments are invalid. Exploring new generelated breast cancer and further clarifing the mechanism of these genes is essential to overcome breast adenocarcinoma metastasis and recurrence.

RSK is a serine-threonine kinase and belongs to the p90 ribosomal S6 kinase family (the 90,000 ribosomal S6 kinase RPS6KA), which is an important downstream effector of Ras-MAPKs signaling cascade (4-6). RSK consists of four isoforms of RSK1, RSK2, RSK3, and RSK4 (7), RSKs play a crucial role in the stimulation of cellular proliferation and survival via phosphorylation and regulation of the transcription factors, kinases, cyclin-dependent kinase inhibitor, p2 $7^{\mathrm{Kip} 1}$, the tumor suppressor, tuberin, and the pro-apoptotic protein, Bad (8-10). An important role for RSKs is suggeted in the regulation of the actin cytoskeleton for cellular migration (11). RSK4 is an outlier and functionally distinct, showing low expression compared with other RSKs, and overexpression of RSK4 may restrict cell growth (12). Several studies have reported that high expression of RSK4 in breast cancer cells is anti-oncogenic, anti-invasive, and anti-metastatic (13), and RSK4 also exhibits a tumor suppressor effect in colon and renal carcinomas (14).

RNA interference (RNAi) is a post-transcriptional process by which double-stranded RNA triggers the degradation 
sequence-specifically. The double-stranded RNA is processed into short, 21- to 22-nucleotide double-stranded RNAs in the cell (15). The use of the RNAi is a powerful tool to block target gene expression has greatly facilitated the understanding of gene function (16).

In the present study, we used Lenti-RSK4-siRNA vectors interfering with expression of RSK4 gene in MCF-7 cells, and investigated its effects on cell proliferation and invasion. In addition, we explored the changes of Ki-67, cyclin D1, CXCR4 and E-cadherin in xenograft tumors.

\section{Materials and methods}

Construction and transfection of shRNAs for RSK4. shRNA targeting human RSK4 gene and a non-targeting RNA were synthesized by GeneChem Technology Co., Ltd. (Shanghai, China). The RNAi sequences that target RSK4 were GATTATC CAAAGAGGTTCT, confirming that there was no homology with other gene by gene database retrieval. Human breast carcinoma MCF-7 cells (Shanghai Institute of Cell Biology) were transfected by lentiviral vector of RSK4-shRNA routinely cultured in $5 \% \mathrm{CO}_{2}$ at $37^{\circ} \mathrm{C}$ in Dulbecco's modified Eagle's medium (DMEM; HyClone, Logan, UT, USA) containing $5 \mu \mathrm{g} /$ $\mathrm{ml}$ polybrene in 6-well plates. The green fluorescent protein GFP expression was observed by fluorescence microscopy (Olympus, Tokyo, Japan) $48 \mathrm{~h}$ after transfection, and cells were collected at $72 \mathrm{~h}$ after transfection for in vivo experiments.

RNA extraction and $q R T-P C R$. Total RNA extraction from different groups used TRIzol reagent (Invitrogen, Carlsbad, CA, USA) according to manufacturer's protocol. The RNA concentration was measured by ultraviolet (UV) light at $260 \mathrm{~nm}$, and the integrity of the extracted total RNA was detected by $1 \%$ agarose gel electrophoresis. Quantitative realtime PCR was performed using SYBR ${ }^{\circledR}$ Premix Ex Taq $^{\mathrm{TM}}$ II (Tli RNaseH Plus) according to the manufacturer's instructions. Primers for RSK4, Ki-67, cyclin D1, E-cadherin, CXCR4 and GAPDH were as follows: RSK4 forward, 5'-ATAT GGACCCACATCAGCGG-3' and reverse, 5'-AGCAGCTAC AGGCTCTAGGA-3' (191 bp); Ki-67 forward, 5'-AGAGAGTG TCTATCAGCCGA-3' and reverse, 5'-CATTGACCTTTGAG GACCAT-3' (157bp); cyclinD1 forward,5'-AGGAACAGAAGT GCGAGGAGG-3' and reverse, 5'-GATGGAGTTGTCGGTG TAGATG-3' (192 bp); E-cadherin forward, 5'-GGTGCTCTTC CAGGAACCTC-3' and reverse, 5'-GGAAACTCTCTCGGT CCAGC-3' (136 bp); CXCR4 forward, 5'-ACCACAGTCATC CTCATCCTG-3' and reverse, 5'-TCTCAAACTCACACCCT TGCT-3' (128 bp); and GAPDH forward, 5'-AAGAAGGTGG TGAAGCAGGC-3' and reverse, 5'-ACCACCCTGTTGCTGT AGCC-3' (200 bp). The reaction conditions for the real-time PCR was $95^{\circ} \mathrm{C}$ for $30 \mathrm{sec}$ followed by 40 cycles of $95^{\circ} \mathrm{C}$ for $5 \mathrm{sec}$ and $60^{\circ} \mathrm{C}$ for $30 \mathrm{sec}$. All reactions were performed in triplicate. Results were analyzed by calculating the $\mathrm{Ct}$ values for target gene and GAPDH using the following formula: $-\Delta \Delta \mathrm{Ct}=$ average $\Delta \mathrm{Ct}$ of control group $-\Delta \mathrm{Ct}$ of the treated group, and the relative expression of target gene in each group was calculated using the $2^{-\Delta \Delta C t}$ method.

Western blot analysis. Cells from different groups were homogenized and lysed in protein extraction reagent (Beyotime,
Shanghai, China). The homogenate was then centrifuged at $12,000 \mathrm{rpm}$ and supernatant was collected as total cell lysate and stored at $-20^{\circ} \mathrm{C}$. The total proteins were applied to a $10 \%$ polyacrylamide gel (Sangon Biotech, Shanghai, China), then electrophoresed, and transferred to polyvinylidene difluoride membranes (Sangon Biotech). The membranes were washed in blocking buffer Tween-20 (TBST; 3X, 5 min each time), incubated with $5 \%$ non-fat milk at room temperature overnight and then the membranes were incubated overnight at $4^{\circ} \mathrm{C}$ with mouse anti-human RSK4 (1:1,000; Santa Cruz Biotechnology, USA) and $\beta$-actin (1:1,000; Boster, Wuhan, China) monoclonal antibodies in blocking buffer. After being washed three times with TBST (3X, 5 min each time), the membranes were treated with secondary anti-mouse antibodies (1:5,000; Boster). Densitometric analysis of western blotting signals was carried out using image-analyzing software. The protein levels were normalized to $\beta$-actin. RSK4 signal values divided by those of the corresponding $\beta$-actin signals (RSK4/ $\beta$-actin) were used for statistical analysis.

MTT assay. The cells transfected with lentivirus RSK4-shRNA, lentivirus negative-shRNA and MCF-7 were harvested, and cell suspension concentration was adjusted to a density of $1 \times 10^{5}$ cells $/ \mathrm{ml}$, plated into a $96-$ well plate $\left(2 \times 10^{3}\right.$ cells $/$ well $)$. Cell proliferation was assessed at 1,2,3,4 and 5 day, following the instructions of the MTT proliferation assay kit (Sigma, USA). The experiment was performed three times.

Transwell migration assay. Transwell plates (24-well) with $8.0 \mu \mathrm{m}$ pore size were coated with Matrigel, which was diluted 1:4 in DMEM, and allowed to gel at $37^{\circ} \mathrm{C}$. Lower chambers were loaded with DMEM containing $10 \%$ FBS. Cell suspensions $\left(5 \times 10^{4}\right.$ cells/well) were added to the upper chambers, and allowed to invade for $48 \mathrm{~h}$ at $37^{\circ} \mathrm{C}$ in a $\mathrm{CO}_{2}$ incubator. The cells in the upper chamber were removed with a swab, fixed in $4 \%$ paraformaldehyde for $30 \mathrm{~min}$. Invasive cells were stained with crystal violet for $30 \mathrm{~min}$ and washed in PBS for $10 \mathrm{~min}$. Invasive cells were counted from five random microscopic fields of each membrane, and the average of cells was calculated. All the experiments in each group were performed in triplicate.

Cell cycle assay. The cells transfected with lentivirus RSK4-shRNA, lentivirus negative-shRNA and MCF-7 were collected, and cell suspension concentration was adjusted to a density of $1 \times 10^{6}$ cells $/ \mathrm{ml}$. The cells were washed with PBS and fixed in $70 \%$ ethanol at $4^{\circ} \mathrm{C}$ overnight. Then cells were centrifuged and washed with PBS to remove ethyl alcohol, and incubated with $50 \mu \mathrm{g} / \mathrm{ml}$ Ribonuclease A at $37^{\circ} \mathrm{C}$ for $30 \mathrm{~min}$. The cells were added with $10 \mu \mathrm{g} / \mathrm{ml} \mathrm{PI}$ and incubated at $37^{\circ} \mathrm{C}$ for $30 \mathrm{~min}$. Finally, cell cycle distribution were analyzed with flow cytometer (Coulter Epics XL; Beckman Coulter, USA).

In vivo study of breast adenocarcinoma xenograft tumor model in nude mice. Animal experiments were approved by the Animal Center Animal Care and Use Committee of Guangxi Medical University. Five-week-old female BALB/c nude mice (weight, 16-20 g) were purchased from Guangxi Medical University Experimental Animal Center. Nude mice 
A

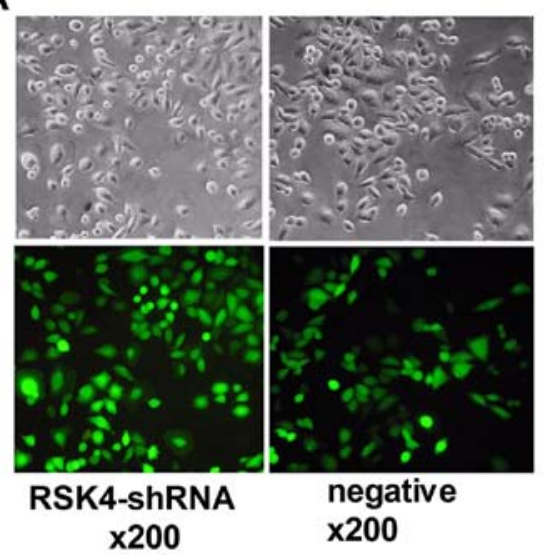

B

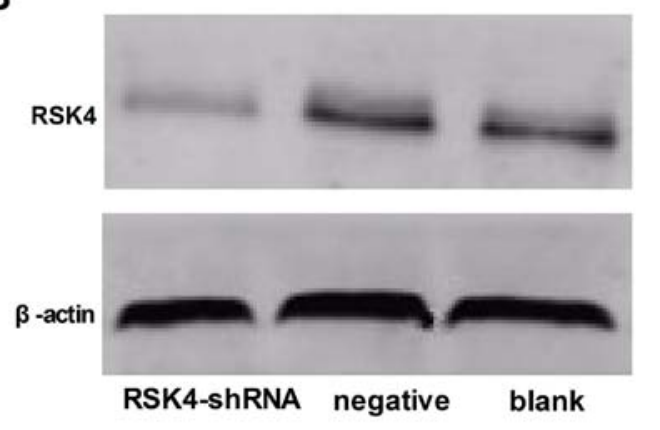

C

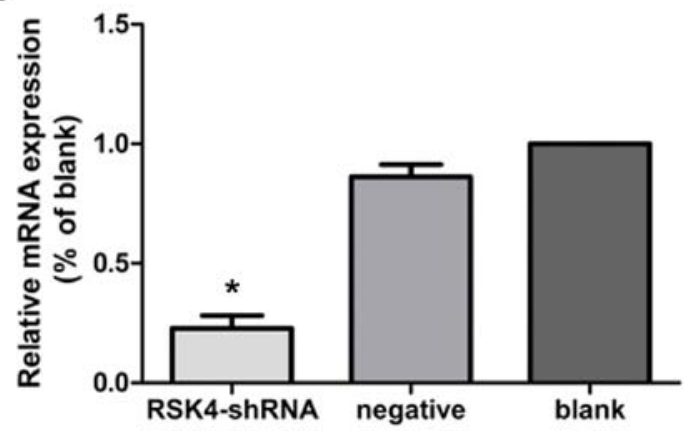

Figure 1. Transfection of MCF-7 cells and identification of lentivirus-mediated RNAi knockdown of RSK4 by western blot assay and qRT-PCR analysis. (A) Lenti-RSK4-shRNA transfected MCF-7 cells show green fluorescence (x200) and Lenti-negative-shRNA transfected MCF-7 cells show green fluorescence (x200). (B) Protein expression of RSK4 in the RSK4-shRNA, negative and blank control groups. (C) Bar graph showing the relative expression levels of RSK4 mRNA in the RSK4-shRNA, negative and blank control groups. ( $\mathrm{P}<0.05$, compared with blank and negative control group).

were fed and housed in laminar flow cabinets, pathogen-free animal facility, at a constant temperature $\left(25-28^{\circ} \mathrm{C}\right)$ and humidity. Mice were randomly divided into three groups with 13 mice/group: lentivirus RSK4-shRNA (RSK4-shRNA), lentivirus negative-shRNA (negative) and MCF-7 control (blank) group. The RSK4-shRNA group of nude mice were subcutaneously injected with MCF-7 cells $\left(5 \times 10^{6}\right)$ carrying lentivirus RSK4-shRNA while the negative control group of nude mice were subcutaneously injected with MCF-7 cells $\left(5 \times 10^{6}\right)$ carrying lentivirus negative-shRNA, and the blank control group of nude mice were subcutaneously injected with MCF-7 cells $\left(5 \times 10^{6}\right)$. After 35 days, the mice were sacrificed, and the tumors and lungs were harvested. Tumor volume was calculated as: Volume $\left(\mathrm{mm}^{3}\right)=$ width $^{2}\left(\mathrm{~mm}^{2}\right) \times$ length $(\mathrm{mm}) / 2$. Consecutive sections were made of every tissue block of the lungs and subjected to $\mathrm{H} \& \mathrm{E}$ histostaining. The incidence of lung metastasis was evaluated independently by two pathologists. The tumors were collected for quantitative real-time PCR. These experiments were repeated three times to confirm the results.

Statistical analysis. All statistical analysis was performed by using SPSS 16.0 (SPSS, Inc., Chicago, IL, USA). One-way analysis of variance (ANOVA), followed by the LSD post hoc test was used to investigate differences between the three groups. Values are expressed as mean \pm standard deviation (SD), and a p-value $<0.05$ was considered statistically significant.

\section{Results}

Transfection efficiency. MCF-7 cells transfected with Lenti-RSK4-shRNA targeting human RSK4 gene or a non-targeting negative control shRNA exhibiting green fluorescence under a fluorescence microscope were considered to be successfully transfected. Under the lentiviral vector $\mathrm{MOI}=10$ conditions, the expression of GFP stability increased after $72 \mathrm{~h}$, and the lentiviral infection rate was high (Fig. 1A).

Effects of lentivirus-mediated RSK4 RNAi on RSK4 mRNA expression by real-time PCR. In the lentivirus RSK4-shRNA, negative control, and blank control groups, the relative expression levels of RSK4 mRNA were $\sim 0.22 \pm 0.06,0.86 \pm 0.05$ and $1.000 \pm 0.00$, respectively. Furthermore, the relative expression levels of RSK4 mRNA in the lentivirus RSK4-shRNA group was significantly lower than levels in the negative $(\mathrm{P}<0.05)$ and blank control groups $(\mathrm{P}<0.05)$, although there was no statistical significance between negative and blank control groups $(\mathrm{P}=0.35$, Fig. $1 \mathrm{C})$.

Effects of lentivirus-mediated RSK4 RNAi on RSK4 expression by western blot assays. In the lentivirus RSK4-shRNA, negative control, and blank control groups, the relative expression levels of RSK4 protein were $\sim 0.16 \pm 0.03,0.57 \pm 0.05$ and $0.49 \pm 0.04$, respectively. The results showed that levels of RSK4 protein in the RSK4-shRNA group was significantly lower than the blank levels $(\mathrm{P}<0.05)$ and negative $(\mathrm{P}<0.05)$ 
A

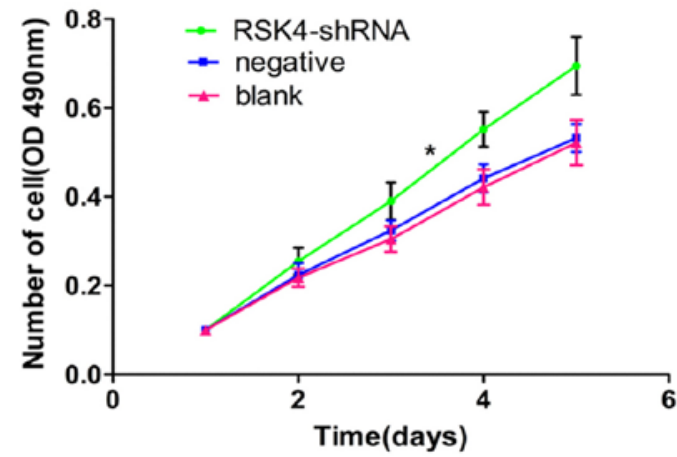

B1

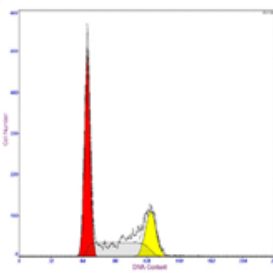

RSK4-shRNA

C1

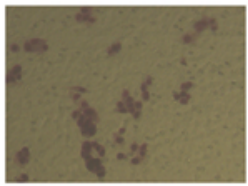

RSK4-shRNA

$\times \mathbf{2 0 0}$

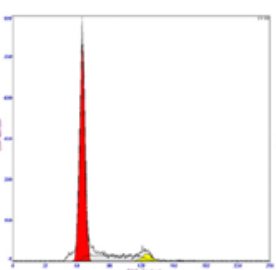

negative

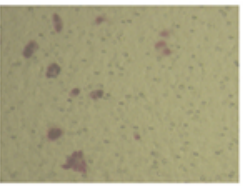

negative

$\times \mathbf{2 0 0}$

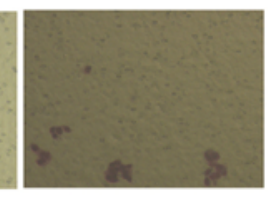

blank

$\times 200$
B2

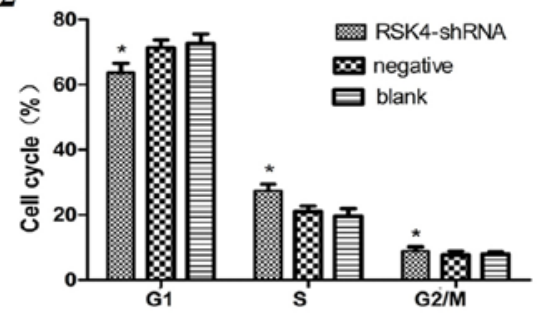

C2

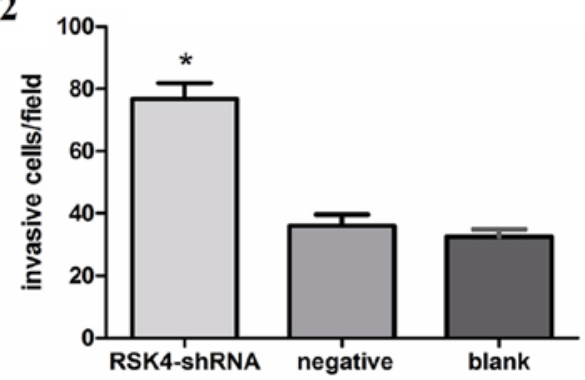

Figure 2. Knockdown of RSK4 promoted proliferation and invasion of MCF-7 cells in vitro. (A) Growth curves of cells in each group. (B1) DNA of MCF-7 cells from the RSK4-shRNA negative, blank control groups by FCM. (B2) Histogram of the percentages of cells in cell cycle phases between the three groups. (C1) The transversed cells in each group in the Transwell experiment. (C2) Histogram of invasion capacity of MCF-7 cells in different groups ( $\mathrm{P}<0.05$, compared with blank and negative control group).

control groups, although there was no statistical significance between negative and blank control groups ( $\mathrm{P}=0.62$, Fig. 1B).

Effect of RSK4 knockdown on the proliferation ability of MCF-7 cells. The MTT assay showed that cell proliferation was significantly promoted in the RSK4-shRNA group as compared to that in the negative and blank control group $(\mathrm{P}<0.05$, Fig. 2A)

Effects of RSK4 knockdown on the cell cycle of MCF-7 cells. The number of cells in the G0/G1 phase in the RSK4-shRNA group $(63.6 \pm 2.8 \%)$ was significantly less $(\mathrm{P}<0.05)$ than that of the negative $(71.3 \pm 2.7 \%)$ and blank control groups $(72.6 \pm 3.0 \%)$, while the number of cells in S phases in the RSK4-shRNA group $(27.4 \pm 1.8 \%)$ was significantly more $(\mathrm{P}<0.05)$ than that of the negative $(21.0 \pm 1.7 \%)$ and blank control groups $(19.5 \pm 2.5 \%)$. However, no significant difference $(\mathrm{P}>0.05)$ in the number of cells in the G2/M phase was found in the RSK4-shRNA group $(8.9 \pm 1.9 \%)$, negative $(7.6 \pm 1.6 \%)$ and blank control groups $(7.8 \pm 1.7 \%)$ (Fig .2B1 and B2).

Effects of RSK4 knockdown on the invasiveness of MCF-7 cells. Transwell cell migration assays showed the capacity of MCF-7 cell enhancement, the number of cells in the RSK4-shRNA group migrated through the Matrigel barriers was more than that of the negative $(76.8 \pm 5.7$ vs. $36.1 \pm 3.4, \mathrm{P}<0.05)$ and blank control groups $(76.8 \pm 5.7$ vs. $32.5 \pm 2.0, \mathrm{P}<0.05)$. No significant difference was observed between the negative group and blank control groups (36.1 \pm 3.4 vs. $32.5 \pm 2.0, \mathrm{P}>0.05)$ (Fig. $2 \mathrm{C}$ ).

In vivo studies of breast adenocarcinoma xenograft tumor model in nude mice. After 35 days, the tumor tissues were harvested and weighed. The xenografts of the RSK4-shRNA group $\left(933.49 \pm 227.51 \mathrm{~mm}^{3}\right)$ had a substantially greater tumors as compared to negative $\left(445.43 \pm 126.45 \mathrm{~mm}^{3}, \mathrm{P}<0.05\right)$ or blank groups $\left(513.68 \pm 141.37 \mathrm{~mm}^{3}, \mathrm{P}<0.05\right)$ (Fig. 3A-C). The mean tumor weight derived from the RSK4-shRNA group $(1.49 \pm 0.25 \mathrm{~g})$ was significantly higher compared to the weights of tumors from the negative $(0.77 \pm 0.22 \mathrm{~g}, \mathrm{P}<0.05)$ and blank control groups $(0.74 \pm 0.18 \mathrm{~g}, \mathrm{P}<0.05)$ (Fig. 3D). The number of lung metastatic lesions in the RSK4-shRNA group was greatly increased compared with the respective negative $(\mathrm{P}<0.05)$ and blank control groups $(\mathrm{P}<0.05$, Fig. $3 \mathrm{E}$ and $\mathrm{F})$.

Effects of lentivirus-mediated RSK4 RNAi on RSK4 mRNA, Ki-67 mRNA, cyclin D1 mRNA,CXCR4 mRNA and E-cadherin 
A

B

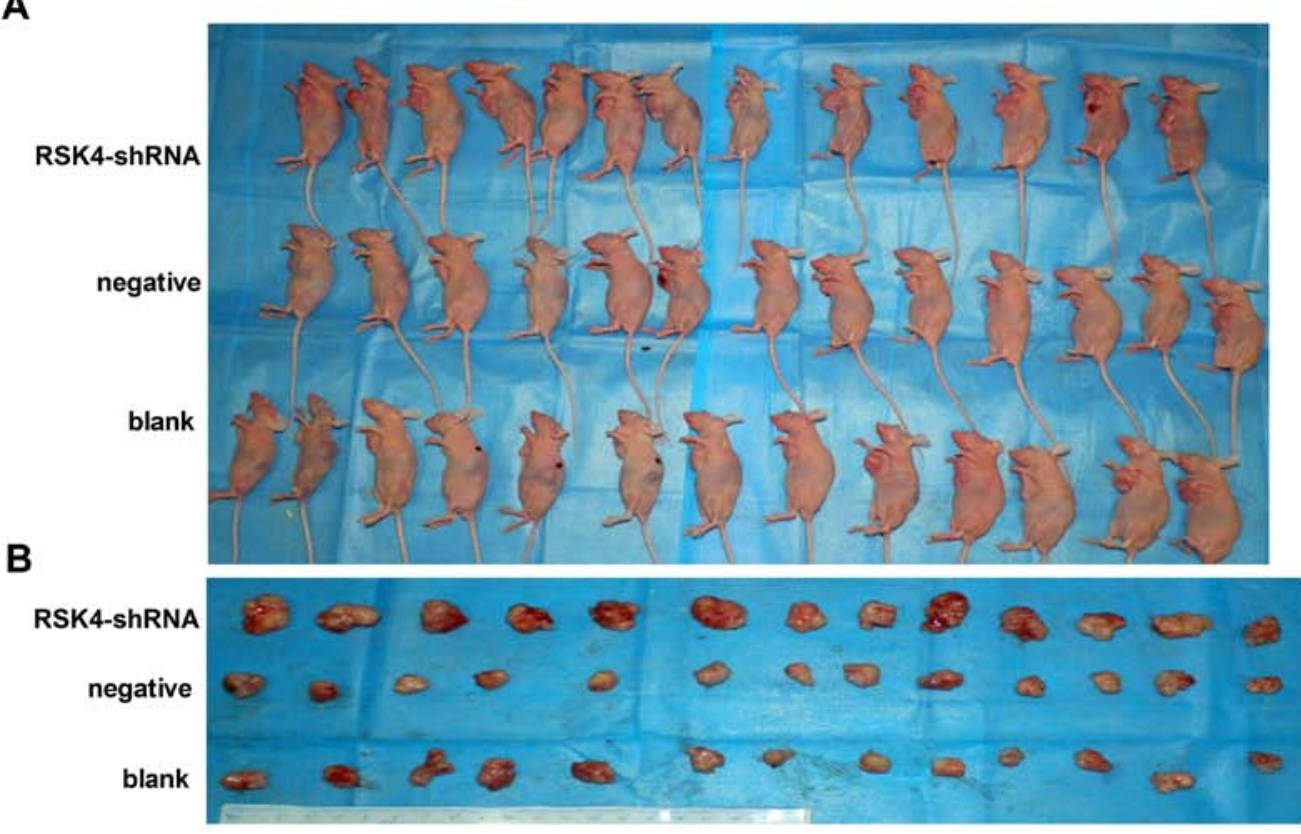

C

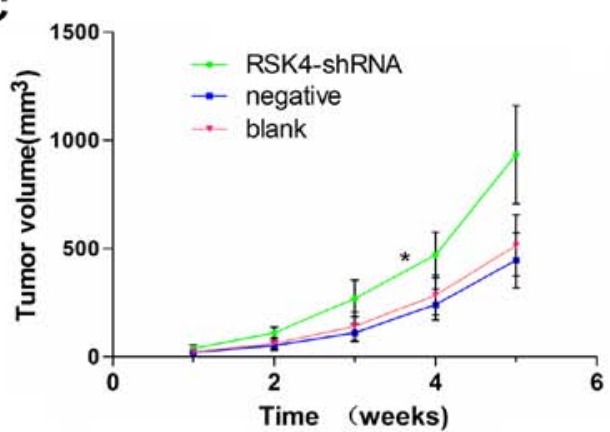

D

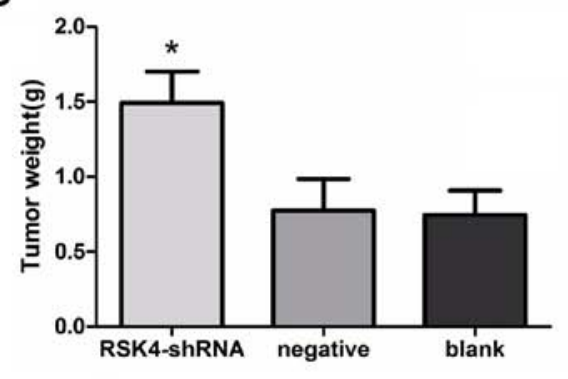

E

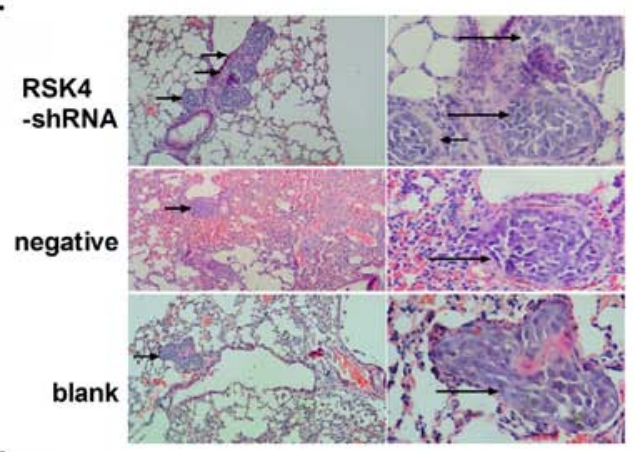

$\mathbf{F}$

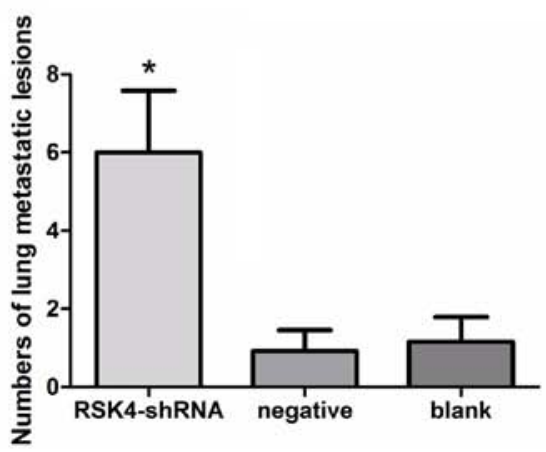

Figure 3. Silencing effect of RSK4 shRNA on in vivo tumor xenograft proliferation and lung metastasis of MCF-7 cells. The mice were sacrificed on day 35, tumor xenografts and the lungs were removed. (A) Xenograft mice at the end of the experiment on day 35. (B) The tumor xenografts dissected from nude mice at the end of the experiment on day 35. (C) Growth curves of tumor xenografts. (" $\mathrm{P}<0.05$, compared with the respective negative control group). (D) Weights of dissected tumors ( $\mathrm{P}<0.05$, compared with blank and negative control group). (E) Representative lung tissue sections from each group (H\&E staining, magnification $\mathrm{x} 100$ and $\mathrm{x} 400$, respectively). (F) The number of the lung metastases lesions in each group ("P<0.05, compared with blank and negative control group).

mRNA expression of tumor xenografts by real-time PCR. In the RSK4-shRNA, negative control, and blank control groups, the relative expression levels of RSK4 mRNA were $\sim 0.32 \pm 0.10,0.88 \pm 0.08$ and $1.000 \pm 0.00$, the E-cadherin mRNA were $\sim 0.42 \pm 0.11,0.82 \pm 0.06$ and $1.000 \pm 0.00$, the CXCR4 mRNA were $\sim 1.48 \pm 0.15,0.82 \pm 0.08$ and $1.000 \pm 0.00$, the Ki-67 mRNA were $\sim 1.44 \pm 0.07,0.87 \pm 0.07$, and $1.000 \pm 0.00$, the cyclin D1 mRNA were $\sim 1.52 \pm 0.09,0.84 \pm 0.08$ and $1.000 \pm 0.00$, respectively. The relative expression levels of RSK4 mRNA and E-cadherin mRNA in the lentivirus RSK4-shRNA group was significantly lower than the levels in the negative (both $\mathrm{P}<0.05$ ) and blank (both $\mathrm{P}<0.05$ ) control groups, while the levels of CXCR4 mRNA, Ki-67 mRNA, cyclin D1 mRNA in the lentivirus RSK4-shRNA group were significantly higher than levels that in the blank (both $\mathrm{P}<0.05$ ) and negative (both $\mathrm{P}<0.05$ ) control groups (Fig. 4). 


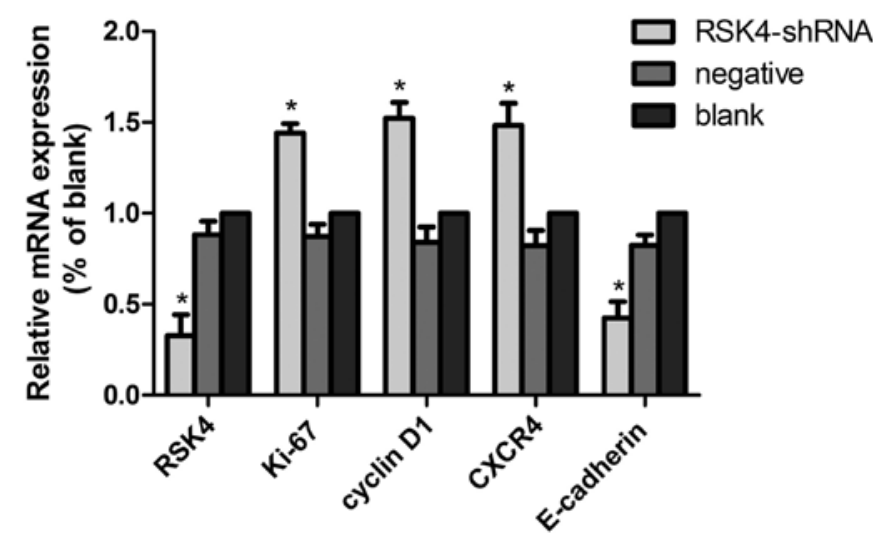

Figure 4. Effects of lentivirus-mediated RSK4 RNAi on RSK4 mRNA, Ki-67 mRNA, cyclin D1-mRNA, CXCR4 mRNA and E-cadherin mRNA expression. Bar graph showing the relative expression levels of RSK4 mRNA, Ki-67 mRNA, cyclin D1 mRNA,CXCR4 mRNA and E-cadherin mRNA in the shRNA, negative and blank control groups $\left({ }^{*} \mathrm{P}<0.05\right.$, compared with the respective negative control group).

\section{Discussion}

Breast cancer is one of the most common cancers and the leading cause of cancer death among females worldwide, and invasion and metastasis is an important prognostic factor in patients with breast cancer, and as a serious threat to women's health. Therefore, further clarifing the mechanism of the development of breast cancer and exploring new therapeutic targets are essential.

Several types of cells were cultured under serum conditions, RSK4 expression was low, but in serum-starved medium, the RSK4 showed high expression, suggesting that RSK4 can restrict cell growth (12). It has been reported that the mouse RSK4 have the ability to inhibit the transcriptional activation of receptor tyrosine kinase (RTK) signaling and extracellular signal-regulated kinase (ERK) signaling on the proliferation of cells (17). Berns et al showed that RSK4 allowed the p53-dependent growth arrest induced by $\mathrm{p} 21^{\text {cip1 }}$ phosphorylation, thus, the knockdown of RSK4 prevented p53-dependent proliferation arrest (18). The above results suggest that RSK4 can inhibit cell proliferation. Thakur et al (19) revealed higher expression of RSK4 was found in normal mammary ductals, and low expression or no expression of RSK4 in benign breast lesions (papilloma). RSK4 is likely to have a role in the development or progression of human breast cancer. This is supported by the finding from Thakur et al study (13). In their study, the overexpressing exogenous RKS4 gene was transfected into the invasive breast cancer cell line MDA-MB231, and compared with its parental cells, the high expression of RSK4 in transfected MDA-MB-231 showed significantly decreased capacity of cell proliferation, migration, invasion, tumorigenesis and metastasis. It suggested that RSK4 may be a tumor suppressor gene in breast cancer, inhibiting cell proliferation, tumorigenesis and metastasis of breast cancer cells, and that downregulation of RSK4 may promote tumorigenesis and metastasis of breast cancer cells.

RNAi is a highly conserved gene silencing mechanism that introduce double-stranded RNA (dsRNA) to trigger the elimination of the target gene (20). RNAi has been widely used as a powerful tool for gene function analysis and ablating specific genes for therapeutic purpose (21). It had been reported that lentivirus vector-mediated expression of RNAi display effective and stable gene silencing (22). Compared with other methods, lentiviral vectors may be feasible.

We proposed a hypothesis that downregulation of RSK4 expression in the MCF-7 cell line would affect breast adenocarcinoma tumorigenesis and metastasis. In order to prove this hypothesis, we used lentivirus-mediated siRNA silencing to knock down RSK4 expression in the breast cancer cell line MCF-7, investigated the effect of the RSK4 gene on the cell proliferation and invasion in vitro, and established a model of xenografts in vivo. In the present study, for the first time we investigated the association between RSK4 expression and human breast adenocarcinoma cell proliferation, migration and metastasis status.

We found that knockdown of RSK4 gene promoted the proliferation and invasion of MCF-7 cells in vitro, and the tumor growth was aggressive in RSK4 shRNA transfected tumors while the growth of negative shRNA-infected xenografts and blank control graft slowed down in the mouse model. Furthermore, knockdown of RSK4 dramatically promoted tumorigenicity and increased the number of lung metastatic lesions. It indicate that RSK4 is implicated in the proliferation, invasion and metastasis of MCF-7 cells, and may be manipulated therapeutically to delay the migration and metastasis of MCF-7 cells. We also found that E-cadherin mRNA were downregulated, whereas Ki-67 mRNA, cyclin D1 mRNA, CXCR4 mRNA levels were increased in the xenograft tumor in nude mice when RSK4 was knocked down. Several studies have showed that cyclin D1 (23-26), Ki-67 $(27,28)$, E-cadherin (29,30), and CXCR4 (31) play important roles in the development of breast carcinoma. It indicated that lentivirus-mediated RNAi knockdown of RSK4 promoted tumor cell proliferation and migration, and the molecular mechanism may associate with changes of Ki-67, E-cadherin, CXCR4 and cyclin D1.

In conclusion, the present study indicated that RSK4 was a significant tumor suppressor gene contributing to breast tumor development. Furthermore, blocking the RSK4 caused genetic instability, and may lead to upregulation of CXCR4, $\mathrm{Ki}-67$, cyclin D1 gene, and downregulation of E-cadherin gene promoting the proliferation and migration of breast cancer cells.

\section{Acknowledgements}

This study was supported by a grant from the National Natural Science Foundation of China (no. 30960427).

\section{References}

1. Jemal A, Bray F, Center MM, Ferlay J, Ward E and Forman D: Global cancer statistics. CA Cancer J Clin 61: 69-90, 2011.

2. Dent R, Valentini A, Hanna W, Rawlinson E, Rakovitch E, Sun P and Narod SA: Factors associated with breast cancer mortality after local recurrence. Curr Oncol 21: e418-e425, 2014.

3. Fischgräbe $J$ and Wülfing P: Targeted therapies in breast cancer: Established drugs and recent developments. Curr Clin Pharmacol 3: 85-98, 2008.

4. Frödin $\mathrm{M}$ and Gammeltoft S: Role and regulation of $90 \mathrm{kDa}$ ribosomal S6 kinase (RSK) in signal transduction. Mol Cell Endocrinol 151: 65-77, 1999.

5. Anjum R and Blenis J: The RSK family of kinases: Emerging roles in cellular signalling. Nat Rev Mol Cell Biol 9: 747-758, 2008. 
6. Nebreda AR and Gavin AC: Perspectives: Signal transduction. Cell survival demands some Rsk. Science 286: 1309-1310, 1999.

7. Yntema HG, van den Helm B, Kissing J, van Duijnhoven G, Poppelaars F, Chelly J, Moraine C, Fryns JP, Hamel BC, Heilbronner H, et al: A novel ribosomal S6-kinase (RSK4; RPS6KA6) is commonly deleted in patients with complex X-linked mental retardation. Genomics 62: 332-343, 1999.

8. Roux PP and Blenis J: ERK and p38 MAPK-activated protein kinases: A family of protein kinases with diverse biological functions. Microbiol Mol Biol Rev 68: 320-344, 2004.

9. Roux PP, Ballif BA, Anjum R, Gygi SP and Blenis J: Tumor-promoting phorbol esters and activated Ras inactivate the tuberous sclerosis tumor suppressor complex via p90 ribosomal S6 kinase. Proc Natl Acad Sci USA 101: 13489-13494, 2004.

10. Yang X, Matsuda K, Bialek P, Jacquot S, Masuoka HC, Schinke T, Li L, Brancorsini S, Sassone-Corsi P, Townes TM, et al: ATF4 is a substrate of RSK2 and an essential regulator of osteoblast biology; implication for Coffin-Lowry syndrome. Cell 117: 387-398, 2004

11. Woo MS, Ohta Y, Rabinovitz I, Stossel TP and Blenis J: Ribosomal S6 kinase (RSK) regulates phosphorylation of filamin A on an important regulatory site. Mol Cell Biol 24: 3025-3035, 2004.

12. Dümmler BA, Hauge C, Silber J, Yntema HG, Kruse LS, Kofoed B, Hemmings BA, Alessi DR and Frödin M: Functional characterization of human RSK4, a new 90-kDa ribosomal S6 kinase, reveals constitutive activation in most cell types. J Biol Chem 280: 13304-13314, 2005.

13. Thakur A, Sun Y, Bollig A, Wu J, Biliran H, Banerjee S, Sarkar FH and Liao DJ: Anti-invasive and antimetastatic activities of ribosomal protein S6 kinase 4 in breast cancer cells Clin Cancer Res 14: 4427-4436, 2008.

14. López-Vicente L, Armengol G, Pons B, Coch L, Argelaguet E, Lleonart M, Hernández-Losa J, de Torres I and Ramon y Cajal S: Regulation of replicative and stress-induced senescence by RSK4, which is down-regulated in human tumors. Clin Cancer Res 15: 4546-4553, 2009.

15. Elbashir SM, Lendeckel W and Tuschl T: RNA interference is mediated by 21- and 22-nucleotide RNAs. Genes Dev 15: 188-200, 2001.

16. Sen GL and Blau HM: A brief history of RNAi: The silence of the genes. FASEB J 20: 1293-1299, 2006

17. Myers AP, Corson LB, Rossant J and Baker JC: Characterization of mouse Rsk4 as an inhibitor of fibroblast growth factor-RAS-extracellular signal-regulated kinase signaling. Mol Cell Biol 24: 4255-4266, 2004.

18. Berns K, Hijmans EM, Mullenders J, Brummelkamp TR, Velds A, Heimerikx M, Kerkhoven RM, Madiredjo M, Nijkamp W, Weigelt B, et al: A large-scale RNAi screen in human cells identifies new components of the p53 pathway. Nature 428: 431-437, 2004.
19. Thakur A, Rahman KW, Wu J, Bollig A, Biliran H, Lin X, Nassar H, Grignon DJ, Sarkar FH and Liao JD: Aberrant expression of X-linked genes RbAp46, Rsk4, and Cldn2 in breast cancer. Mol Cancer Res 5: 171-181, 2007.

20. Sharp PA: RNA interference - 2001. Genes Dev 15: 485-490, 2001.

21. Hannon GJ and Rossi JJ: Unlocking the potential of the human genome with RNA interference. Nature 431: 371-378, 2004.

22. Stewart SA, Dykxhoorn DM, Palliser D, Mizuno H, Yu EY, An DS, Sabatini DM, Chen IS, Hahn WC, Sharp PA, et al: Lentivirus-delivered stable gene silencing by RNAi in primary cells. RNA 9: 493-501, 2003.

23. McIntosh GG, Anderson JJ, Milton I, Steward M, Parr AH, Thomas MD, Henry JA, Angus B, Lennard TW and Horne CH: Determination of the prognostic value of cyclin D1 overexpression in breast cancer. Oncogene 11: 885-891, 1995.

24. Vos CB, Ter Haar NT, Peterse JL, Cornelisse CJ and van de Vijver MJ: Cyclin D1 gene amplification and overexpression are present in ductal carcinoma in situ of the breast. $\mathrm{J}$ Pathol 187: 279-284, 1999.

25. Oyama T, Kashiwabara K, Yoshimoto K, Arnold A and Koerner F: Frequent overexpression of the cyclin D1 oncogene in invasive lobular carcinoma of the breast. Cancer Res 58: 2876-2880, 1998.

26. Bilalović N, Vranić S, Basić H, Tatarević A and Selak I: Immunohistochemical evaluation of cyclin D1 in breast cancer. Croat Med J 46: 382-388, 2005.

27. Niewiadomska H, Jeziorski A and Olborski B: The expression of the proliferating antigen Ki67, PCNA and products of suppressor gene 533 in primary invasive ductal breast carcinoma. J Exp Clin Cancer Res 17: 503-510, 1998.

28. Zhou CJ, Zhang QH, Zhang TG, Sun SZ, Li H, Wang Y and Liu ZY: Expression of ER, Ki-67 and cylinD1 in the pre-cancerous breast of Chinese patients. Pathol Oncol Res 15: 153-158, 2009.

29. Shargh SA, Sakizli M, Khalaj V, Movafagh A, Yazdi H, Hagigatjou E, Sayad A, Mansouri N, Mortazavi-Tabatabaei SA and Khorram Khorshid HR: Downregulation of E-cadherin expression in breast cancer by promoter hypermethylation and its relation with progression and prognosis of tumor. Med Oncol 31: $250,2014$.

30. Siitonen SM, Kononen JT, Helin HJ, Rantala IS, Holli KA and Isola JJ: Reduced E-cadherin expression is associated with invasiveness and unfavorable prognosis in breast cancer. Am J Clin Pathol 105: 394-402, 1996.

31. Furusato B, Mohamed A, Uhlén M and Rhim JS: CXCR4 and cancer. Pathol Int 60: 497-505, 2010. 